\title{
Refining the Street Children with Education
}

\author{
Sarah Alam*, Prof. Dr. M. Abuzar Wajidi \\ Under the Supervision of
}

\begin{abstract}
Street Children are known in the developed world for several decades but in Pakistan this term has recently become familiar to people when the street children of Pakistan exhibited a flying-color performance in football competitions held among teams comprising of street children from various countries. The media prominently highlighted the achievement of the Pakistani street children who were presented some awards by the provincial government of Sindh while appreciated throughout the country. For the entire society, the achievement of these children is a significant message that despite their homelessness or alienation from the common family set up, they bear lot of potentials like any other children of the society, they have the willingness and strength to rise and improve. Keeping aside the excepted above street children who won competition, it is observable that street children, particularly of the developing countries including Pakistan, have to live a very tough life posed to multiple threats like health, physical assault and violence etc. This deeply deplorable condition can be improved with the help of education. Education of the street children can transform them into useful and responsible citizens and members of the society by way of developing among them awareness about their role in the society, their basic human rights and responsibilities, self-respect and respect for others.
\end{abstract}

Key words: Street Children, Education, society

\section{Introduction}

Street Children are usually the victims of poverty, lost or missing social values and domestic violence - either or both physical and mental violence. Children turn into street children when they find no better place than streets to live on. They come to streets out of despair and desperation. Poverty is the main cause of bringing these children to streets as they lack basic necessities of life like food, clothing, shelter and health facilities (Shukla 2005). Millions of children are street children in the world today. It is a pity that socio-economic issues are causing an uneven increase in the population of street children worldwide thus supporting the growth of different evils in the society (Scheper-Hughes, 2004) These children are posed to various harmful consequences like poor health, deplorable living environment, physical abuse, sexual abuse and other serious issues. Although NGOs and charity organizations do extend support for the street children, yet this is not enough.

\section{Statement of the Problem}

Like all other children, the street children also ought to be self-sufficient and socially and strongly linked with the society. They need to be motivated to become a productive part of the society. To make this idea come true, the street children need to be educated. They require street education. This education can improve the quality of their life. They would need education, awareness and information through this education to learn the ways that could improve their health condition, alleviate their poverty, take them out of several sorts of threats they face in their everyday life on streets, awareness about child or forced labor, harms of drugs, protection against sexual abuse etc. They also need to be encouraged to get literate and associate to education system which can in future transform their homeless status and enable them have their own homes.

\section{Objectives of the Research}

The research will consider probabilities of betterment of the street children with the help of education and skill development with the firm hope that this will improve their economic situation and, in turn, the quality of their life which will have a direct impact on the improvement of the society at large in terms of drastic reduction in the social evils and crimes.

Another purpose of the research paper is to introduce the street children to the society of Pakistan which is mostly not familiar with the street children as 'street children'. A proper understanding of these children will help the society realize their problems and grievances and ultimately build a bridge of communication between the two instead of ignoring these street children. 


\section{Research Methodology}

As the problem of street children is well recognized in the world, especially in the developed world, and keeping in view the title of the research paper, it has been considered appropriate to apply the qualitative method of research for this paper.

\section{Literature Review}

Street children are not the issue in the developing countries alone, they are found in large numbers all around the world. The conception of street or homeless children varies from country to country and culture to culture for the reason that in national census, the population of street or homeless children is not sufficiently represented. According to Shukla (2005), the number of street children stays somewhere between 10 to 100 million in the world. Most of these children are found in major cities of the developing countries. There are about 40 million street children in Latin America, 25 to 30 million in Asia and more than 10 million in the continent of Africa. Nearly 80 percent of these children are males.

In Europe it was Charles Dickens who, through his popular stories authored between 1838 to 1839 focused attention of the society on the life of the homeless street children and brought forth their hardships and grievances. For his services, this great writer is remembered as a social reformer (Warren, 2011).

Street children constitute a significant social issue in Pakistan like in India and other developing countries. The number of street children in these countries is rapidly rising due to the phenomenon that poor masses from rural areas migrate to cities to earn their living (Behura \& Mohanty, 2005). They usually settle in slums, asphalts, congested dilapidated areas, railway stations and similar places. The street children are given different names in different parts of the world. In the continent North America they are referred to as homeless youth, runaways or throwaways. In the developing countries they are given various titles like parking boys (in Kenya), Pogey-boys (in Philippines), Pivets (in Brazil) while in India they are called rag-pickers. In Peru people call the street boys 'pajaro-frutero' which means fruit bird while in Zaire they are called 'moineaox' meaning sparrow and in Cameroon these children are termed as 'poussins' i.e. chicks.

The subject of street children is recognized by the global community. On account of the adverse consequences of the children remaining street children, the United Nations expressed its concern over the issue two decades ago in 1994. For the sake of conducting an organized research so as to resolve the problems concerning the street children, an official model was designed for the rehabilitation of the street children all over the world.

The research scholar is of the strong view that like all other children, street children when provided with the opportunity of education, can be transformed into better human beings and compatible citizens for their societies. Education for these children is of vital importance because without education, it is apprehended that these children can be a source of violence and delinquency in the society (Scanlon et al, 1998). In Pakistan, the state of affairs relating to street children is also not fair at all. Information coming through various media channels reveals that street children are victims of mal-nutrition, rape, incest, prostitution, trafficking and transsexuals. A large number of these children are involved in crimes of various degrees and in drug abuse. They are exploited by different gangs. It is a sad reality that on government level, no concrete measures are initiated to address the issue of street children. Although some Non-Government Organizations (NGOs) are making efforts in this direction, but without support of the government and the society itself, it is a hard challenge to transform these children into useful and peaceful citizens. Needless to say that without rehabilitation of the street children it would be impossible to see a peaceful and a safe society around. The best way is to develop among the communities adequate awareness about the consequences of the increasing number of the street children in the society and the need to educate the street children who are usually exposed to severe risks including physical assault, physical violence and sexual abuse as well as health issues. In case where street children are young girls, complexities emerge even more seriously. A large segment of the street children are teenagers. In Pakistan there is still no exact idea about the number of the street children. However, most of these street children belong to large cities of Karachi and Lahore.

\section{Education as a Right of Street Children}

Although most of the street children are involved in unhealthy activities, yet it would be wrong to guess that they like to continue with the same conditions. On the International Street Children's Day observed on April 12, 2014 in Islamabad, more than 60 children belonging to the slums of the capital city, and getting education at the Out-of-School Children's School (OSCS) demanded necessary measures by the government for their rehabilitation in society. In their demand, the children expressed strong wish to get education in order to earn respect as responsible citizens. They complained that they were denied admission in public and private sector schools. The children also proteste that they were treated in the society as the rejected lot. Some of the students of OSCS faced language hurdles as they belonged to other parts of the country and were unable to follow the medium of instruction offered in the OSCS. Since education is one of the basic human rights of 
which the street children are largely deprived, this deprivation needs to be considered as a potential source of human rights violation. Street children may be street-based or home-based. However, children of both the categories are the unprivileged part of the society in Pakistan and elsewhere.

The United Nations Convention on the Rights of Child enacted about 24 years ago in September 1990 described the important areas of the rights and interests of children. Of these rights, health and education are very significant. It must be emphasized that keeping the Street Children away from education refer to keeping them away from the society and the social order.

For various reasons and circumstances the street children have to support their parents or their younger siblings. Grave economic conditions constrain parents to put their young children to work and earn living. In many cases the children do not have parents, and they have to live with their relatives where they usually face humiliation and negative attitudes and behavior of with whom they live. These parents or the relatives fail to realize the value of education. They sacrifice these children's future life to the present situation. There is much need to develop among these parents and relatives or other guardians of the street children necessary awareness about the value and exigency of education in life.

Schools in public and private sector should be convinced through social campaign to accept the school children for enrolment. Depending on the degree of unusual behavior and attitude issues, separate classes may be arranged for the education and training of these unprivileged children. Besides, teachers during the training and education of the street children will require to address the emotional needs, behavioral psychology and rights of children in particular. Education must be provided to the street children as their right and not as some favor. Therefore, no discrimination should also exist in the quality of education for these children.

The World Education Form organized in Senegal, Dakar a framework of action under the title Education for All (EFA) in the year 2000. The expanded commentary drafted on this framework describes that a number of governments and agencies limited their efforts only to some selected, in- easy-access areas for basic education, and overlooked other areas. This means that children of the remote rural areas fail to benefit from the opportunity of basic education. Countries highlighted for want of basic education include the regions of South Asia and sub-Saharan Africa. The Framework observes that in some countries, passing the cost burden on to the poor parents has had a devastating impact on enrolment and retention. It insists that education must neither exclude nor discriminate. Every government has the responsibility to provide free, quality basic education, so that no child will be denied access because of any inability to pay.

The government of Pakistan and the non-government organizations operating in the country must consider the phenomenon of globalization as an opportunity as well as a challenge. Keen participation in the globalization can help poor and developing countries of the world in extending their opportunities for basic education for the children generally and for the street children particularly. Training, education and skill development among the street children can develop their self-confidence and self-esteem.

\section{Recommendations}

The street children in the large cities of Pakistan like Karachi and Lahore are in large numbers. The uneven growth rate of population is deteriorating the situation of street children even worse. The rapidly embellishing unemployment and the consequent crime rate in these cities have particularly placed the society at grave risks. In this scenario, the street children, who generally lack proper guidance about living a life free of crimes, are obviously in greater need of rehabilitation through education than others. The issue of their education is to be taken up on war-footing by the government, the civil society and the NGOs. Needless to say, that otherwise, the present state of affairs of law and order in the entire country, especially in the mega cities, is eye-opener. There is need to make organized and systematic efforts to prepare a database of the street children and maintain all details necessary to prepare rehabilitation, education and training programs for them. For many street children formal education may be impracticable, so these children must be afforded informal education like the Out-of-School Children's Schools (OSCSs). Depending on the potentials, other street children may be engaged in technical training and skills development. The process and techniques of educating the street children must be friendly and simple. These children would need more sympathy and affection than others. At the same time their comparatively rough behavior may require their teachers exhibit increased tolerance and patience - the attribute that are vital keys to success and progress. It is education that will create awareness in them about the rights of children and the human rights. 


\section{References}

1 Shukla P.C. (ed.) (2005), 'Street Children and The Asphalt Life (Delinquent Street

\section{Children), Isha Books, Delhi}

[1]. Scheper-Hughes, N. (2004), Dangerous and Endangered Youth: Social Structures and Determinants of Violence in Ann N Y Acad Sci. 2004 Dec; 1036:13-46.

[2]. Warren A. (2005), Charles Dickens and Street Children of London, Harcourt Publishing Company, New York.

[3]. Behura, N.K. \& Mohanty, R.P. (2005), Street Children and Their Problems, Discovery Publishing House, New Delhi.

[4]. Pandey, 1991: 15-18 in Behura, N.K. \& Mohanty, R.P. (2005), 'Street Children and Their Problems', Discovery Publishing House, New Delhi.

[5]. Scanlon, T.J., Tomkins, A.,.Lynch, M. A, and Scanlon, F. (1998), Street Children in Latin America, 316 Brit. Med. J. 1596 , 1597 (1998).

[6]. http://tribune.com.pk : article in The Express Tribune dated May 01, 2014 retrieved on May 14, 2014.

[7]. www.unesco.org/ education - The Dakar Framework of Action, retrieved on May 14, 2014. 